\title{
A INTERPRETAÇÃO NO DIREITO INTERNACIONAL PRIVADO
}

\section{INTERPRETATION IN PRIVATE INTERNATIONAL LAW}

\author{
Luís DE LiMA PINHEIRO \\ Professor Catedrático da Faculdade de Direito \\ da Universidade de Lisboa \\ Recibido: 18.06.2020 / Aceptado: 01.07.2020 \\ DOI: https://doi.org/10.20318/cdt.2020.5743
}

\begin{abstract}
Resumo: O presente estudo tem por objeto a metodologia da interpretação jurídica em Direito Internacional Privado. O Direito Internacional Privado é aqui considerado como disciplina jurídica que abrange o Direito de Conflitos, o Direito da Competência Internacional e o Direito de Reconhecimento (de decisões estrangeiras). Para além de aspetos gerais, é abordada a especificidade da interpretação das normas internas (na ordem jurídica portuguesa) e das normas supraestaduais (internacionais e da União Europeia).

Procura-se demonstrar que os problemas específicos colocados pela interpretação das proposições jurídicas de Direito Internacional Privado apresentam uma vasta identidade no Direito de Conflitos, no Direito da Competência Internacional e no Direito de Reconhecimento, que contribui para justificar a visão abrangente da disciplina jurídica em causa.

Palavras chave: interpretação em Direito Internacional Privado, interpretação da norma de conflitos, interpretação da norma de competência internacional, interpretação da norma de reconhecimento, qualificação.
\end{abstract}

\footnotetext{
Abstract: The object of this essay is the methodology of legal interpretation in Private International Law. Private International Law is considered here as a legal subject that comprises Choice of Law, Jurisdiction and Recognition of Judgments. Besides general considerations, the specificity of the interpretation of domestic rules (in the Portuguese legal order) and of supranational rules (international and from the European Union) is addressed.

The essay pleads for a wide identity of the specific issues arising from the interpretation of Private International Law provisions on the Choice of Law, Jurisdiction and Recognition of Judgments, which reinforces the justification for a broad view of the legal subject at stake.

Keywords: interpretation in Private International Law, choice of law rule interpretation, jurisdiction rule interpretation, recognition of judgments rule interpretation, characterization.

Sumário: I. Aspetos Gerais. II. Interpretação das normas de conflitos. 1. Generalidades. 2.Interpretação dos conceitos utilizados para delimitar a previsão da norma de conflitos. 3. Interpretação dos conceitos designativos do elemento de conexão. III. Interpretação das normas de competência internacional. 1. Aspetos gerais. 2. Normas de competência internacional de fonte interna. 3. Normas de competência internacional de fonte supraestadual. iv. Interpretação das normas de reconhecimento. 1. Aspetos gerais. 2. Normas de reconhecimento de fonte interna. 3. Normas de reconhecimento de fonte supraestadual. V. Considerações Finais.
} 


\section{Aspetos Gerais}

1. A regulação jurídica das situações transnacionais coloca três problemas específicos. Primeiro, o problema da determinação do Direito aplicável: perante uma situação que apresenta contactos relevantes com mais de um Estado soberano é necessário determinar o Direito que a vai disciplinar juridicamente. Segundo, o problema da competência internacional: perante a eclosão de um litígio relativamente a uma situação transnacional torna-se necessário, na falta de convenção de arbitragem, determinar os tribunais estaduais competentes para o dirimir. Enfim, o problema do reconhecimento de decisões estrangeiras, que se coloca, designadamente, quando o litígio é decidido por um tribunal estrangeiro e se pretende que a decisão produza efeitos na ordem jurídica local. Trata-se então de saber se a decisão estrangeira pode produzir efeitos na ordem jurídica local e, em caso afirmativo, sob que condições.

2. Enquanto disciplina jurídica, o Direito Internacional Privado estuda a resolução de todos estes problemas, abrangendo, por conseguinte, o Direito de Conflitos, o Direito da Competência Internacional e o Direito de Reconhecimento. Na ordem jurídica portuguesa, as fontes destes complexos normativos são essencialmente supraestaduais (internacionais e europeias) e internas ${ }^{1}$.

Os critérios de interpretação aplicáveis são os que regem a interpretação de cada uma destas categorias de fontes.

3. Relativamente às normas de fonte interna, deve ter-se em conta o disposto nos arts. $8 .^{\circ} \mathrm{e} 9 .^{\circ}$ $\mathrm{CC}$ e a metodologia desenvolvida pela ciência jurídica.

4. Quanto às normas de fonte internacional, há que atender às regras próprias que se estudam no Direito Internacional Público e, designadamente, ao disposto no art. $31 .^{\circ}$ da Convenção de Viena sobre o Direito dos Tratados.

As principais normas de fonte internacional a ter em conta são as que constam de Convenções de unificação do Direito de Conflitos, do Direito da Competência Internacional e do Direito de Reconhecimento. Nos termos do . $^{\circ} 1$ do art. $31 .^{\circ}$ da Convenção de Viena, um "tratado deve ser interpretado de boa fé, de acordo com o sentido comum a atribuir aos termos do contrato no seu contexto e à luz dos respetivos objeto e fim". Decorre do sentido e do fim das Convenções de unificação que a interpretação das suas proposições tem de ser autónoma relativamente às ordens jurídicas nacionais individualmente consideradas e assentar numa comparação de Direitos ${ }^{2}$. Só desta forma se pode promover a uniformidade de interpretação das proposições convencionais pelas diferentes jurisdições nacionais ${ }^{3}$.

Esta preocupação foi expressa no art. $18 .^{\circ}$ da Convenção de Roma sobre a Lei Aplicável às Obrigações Contratuais, inspirado no n. ${ }^{\circ} 1$ do art. $7^{\circ}$ da Convenção das Nações Unidas sobre Venda Internacional de Mercadorias, segundo o qual na "interpretação e aplicação das regras uniformes que antecedem. deve ser tido em conta o seu caráter internacional e a conveniência de serem interpretadas e aplicadas de modo uniforme".

Nesta interpretação deverão especialmente ser tidos em conta os fins do Direito Internacional Privado que estão subjacentes ao Direito unificado, bem como os fins gerais do Direito Internacional Privado comuns aos sistemas dos Estados contratantes.

5. No que toca às normas de fonte europeia, valem os critérios de interpretação reconhecidos pela jurisprudência e pela doutrina europeias, em que se salientam os critérios teleológicos que atendem

\footnotetext{
${ }^{1}$ Sobre a evolução histórica da função interpretativa no Direito de Conflitos, ver SALERNo [2016: 687 e segs.].

${ }^{2}$ Ver Kropholler [2006: 125] e art. 2. ${ }^{\circ} / 2$ da Lei italiana de Direito Internacional Privado.

${ }^{3}$ De modo algo diverso se colocam as coisas relativamente ao Direito Internacional de Conflitos, uma vez que se trata de normas de conflitos aplicáveis por jurisdições internacionais ou quási-internacionais. Aqui a uniformidade de interpretação está garantida. De todo o modo, é claro que se trata também de uma interpretação autónoma relativamente às ordens jurídicas nacionais, que tem de atender aos fins do Direito Internacional de Conflitos.
} 
não só ao fim da norma em causa, mas também às finalidades prosseguidas com os tratados instituintes e aos princípios gerais de Direito da União Europeia ${ }^{4}$.

Avultam as normas contidas em Regulamentos da União Europeia em matéria de conflitos de leis, competência internacional e reconhecimento de decisões estrangeiras. A interpretação das proposições destes Regulamentos também deve ser autónoma ${ }^{5}$. Isto significa que não deve ser feita referência ao Direito de um dos Estados em presença, mas antes ter em conta "o contexto da disposição e o objetivo prosseguido pelas normas em causa" $\mathrm{e}$ a conformidade com "os direitos fundamentais protegidos pela ordem jurídica comunitária ou com outros princípios gerais do direito comunitário"?.

Tratando-se de Convenções que estão ligadas à União Europeia ou de Regulamentos da União Europeia, justifica-se, a par de outros critérios de interpretação relevantes ${ }^{8}$, o recurso a uma interpretação comparativa que atenda aos "princípios gerais" que resultam do conjunto das ordens jurídicas dos Estados-Membros ${ }^{9}$.

Na falta de concordância geral, seria defensável que se atendesse às soluções reconhecidas nos Estados-Membros mais interessados, mas o Tribunal de Justiça da União Europeia (doravante TUE) e a doutrina tendem a ter em conta as soluções reconhecidas na maioria dos Estados-Membros ${ }^{10}$.

6. Os tribunais dos Estados-Membros, quando aplicam atos normativos da União, devem respeitar a jurisprudência do TUE e podem ou devem submeter ao mesmo tribunal questões de interpretação dos mesmos atos que ainda não tenham sido por ele decididas. O mesmo se diga da aplicação de Convenções ligadas às União Europeia quanto tiver sido atribuída ao TUE a mesma competência interpretativa.

7. Feitas estas considerações gerais, passo a examinar os aspetos específicos da interpretação das normas de conflitos (II), das normas de competência internacional (III) e das normas de reconhecimento (IV).

\section{Interpretação das normas de conflitos}

\section{Generalidades}

8. Como decorre do anteriormente exposto, a interpretação do Direito de Conflitos tem por objeto proposições de fonte internacional, europeia ou interna.

Também podem suscitar-se problemas de interpretação de proposições conflituais estrangeiras quando haja lugar à aplicação de Direito Internacional Privado estrangeiro, como sucede, designadamente, na devolução e na aplicação de normas de remissão condicionada. As proposições conflituais estrangeiras devem ser interpretadas segundo os critérios que lhes forem aplicáveis no sistema a que pertencem.

9. Os problemas de interpretação podem dizer respeito a qualquer dos elementos da norma de conflitos.

O problema da interpretação coloca-se frequentemente com respeito aos conceitos utilizados na delimitação do objeto da remissão, por exemplo, os conceitos de "capacidade", "forma", "obrigação contratual" e "casamento".

\footnotetext{
${ }^{4}$ Ver Fausto de Quadros [2013: n. ${ }^{\circ}$ 237] e Oppermann/Classen/Nettesheim [2014: n. ${ }^{\circ}$ 176].

5 Ver também TCE 14/10/1976, no caso Eurocontrol [CTCE (1976) 629], e Kropholler [2006: 79 e seg.].

${ }^{6}$ Cf. TCE 2/4/2009, no caso $A$. (proc. C-523/07) [in http://curia.europa.eu], n. ${ }^{\circ} 34$, relativamente ao Regulamento Bruxelas II bis.

${ }^{7}$ Cf. TCE 23/12/2009, no caso Deticek [in http://curia.europa.eu], n. ${ }^{\circ} 34$, relativamente ao Regulamento Bruxelas II bis.

${ }^{8}$ Ver, com mais desenvolvimento, Kropholler [2006: 79 e segs.] e Magnus/Mankowski/Magnus [2016: n. ${ }^{\circ}$ s 98 e segs.].

${ }^{9}$ Assim tem entendido o TCE/TUE, desde o ac. 14/10/1976, no caso Eurocontrol [CTCE (1976) 629].

${ }^{10}$ Ver Kropholler [2006: 81] e Magnus/Mankowski/Magnus [2016: n. ${ }^{\circ}$ 108], com extensas referências jurisprudenciais.
} 
Também se pode colocar quanto aos conceitos que exprimem o elemento de conexão, sobretudo quando forem conceitos técnico-jurídicos como, por exemplo, "nacionalidade" e "lugar do dano".

Enfim, a estatuição da norma de conflitos, quanto à determinação das normas materiais que irão ser efetivamente aplicadas, também suscita problemas de interpretação e aplicação.

10. As normas de conflitos de fonte interna têm de ser interpretadas como parte do sistema jurídico português. Na determinação do sentido e alcance dos conceitos técnico-jurídicos utilizados quer para delimitar o objeto da remissão quer para designar o elemento de conexão há que partir do Direito material interno, do conteúdo aí atribuído, por exemplo, a "capacidade", "forma", "obrigações", "direitos reais", "nacionalidade", "residência habitual", etc.

Mas se a interpretação é ancorada no Direito material interno, ela não lhe está subordinada.

A especialidade do Direito de Conflitos, que tem de lidar com ordens jurídicas estrangeiras e, por vezes, com Direito extra-estadual, obriga a que a interpretação dos conceitos da norma de conflitos tenha em conta os fins próprios do Direito Internacional Privado. Daí decorre que se possa atribuir a estes conceitos um sentido e alcance diferente do dos conceitos homólogos do Direito material interno.

A interpretação da norma de conflitos é, por isso, uma interpretação autónoma relativamente ao Direito material interno.

11. Quanto aos critérios gerais de interpretação das proposições jurídicas internacionais e europeias remete-se para o anteriormente exposto.

12. Nas próximas alíneas concretizarei estes critérios com respeito aos conceitos utilizados na previsão da norma de conflitos (2) e aos conceitos designativos do elemento de conexão (3). Não me ocuparei de problemas específicos de interpretação e aplicação da norma de conflitos que, correspondendo a vastas áreas da Parte Geral do Direito de Conflitos, não cabe analisar numa obra dedicada à interpretação e não seria de todo modo possível abarcar neste estudo ${ }^{11}$.

\section{Interpretação dos conceitos utilizados para delimitar a previsão da norma de conflitos}

13. A interpretação dos conceitos utilizados para delimitar a previsão da norma de conflitos relaciona-se com o tema da qualificação em Direito Internacional Privado.

Com efeito, numa aceção ampla, a qualificação abrange os problemas de interpretação e aplicação da norma de conflitos que dizem respeito aos conceitos técnico-jurídicos utilizados na sua previsão.

Por exemplo, os conceitos de "estado", "capacidade", "relações de família", "sucessões por morte", "obrigações contratuais", "direitos reais".

Estes conceitos delimitam o objeto da remissão. O objeto da remissão são situações da vida ou aspetos de situações da vida transnacional.

14. Não deve isolar-se a interpretação da aplicação, nem a delimitação do âmbito de aplicação da norma do apuramento das circunstâncias do caso relevantes para a sua aplicação. O aplicador tem de fazer um vaivém entre a norma o caso, o qual se vem a traduzir quer numa adaptação da norma às circunstâncias do caso quer num enriquecimento do conteúdo dos conceitos a que recorre a previsão normativa.

Os problemas que estudamos dentro da qualificação em sentido amplo são, pois, fundamentalmente, problemas de interpretação da norma de conflitos ${ }^{12}$.

15. Tradicionalmente, a qualificação é encarada segundo um esquema subsuntivo, baseado na lógica formal, o silogismo de subsunção.

\footnotetext{
${ }^{11}$ Estes problemas colocam-se com respeito à concretização do elemento de conexão; à remissão para ordens jurídicas complexas; à devolução; à fraude à lei; e a problemas especiais de interpretação e aplicação do Direito de Conflitos.

${ }^{12}$ No mesmo sentido, Maury [1936: 469]; MaKarov [1949: 28]; e Kegel/Schurig [2004: 336].
} 
Assim, em sentido amplo, o problema da qualificação envolve três momentos.

No primeiro momento, estabelece-se a premissa maior, que é a previsão da norma de conflitos. O estabelecimento desta premissa envolve a interpretação da proposição jurídica, por forma a determinar a previsão normativa, mediante um enunciado das suas notas conceptuais.

No segundo momento, estabelece-se a premissa menor, por meio de uma delimitação do objeto da remissão, i.e., da determinação das situações da vida que se vão subsumir. Esta delimitação é feita tendo em atenção notas características jurídicas, envolvendo, pois, uma caracterização das situações da vida. Em rigor, a premissa menor não é constituída por factos ${ }^{13}$, mas por um enunciado de que as notas características da previsão normativa se encontram preenchidas em determinada situação da vida.

O terceiro momento é a subsunção, traduzindo-se na recondução da matéria delimitada na previsão normativa. Corresponde à qualificação em sentido estrito ${ }^{14}$. É um momento largamente predeterminado pelos dois anteriores.

16. Relativamente a este esquema subsuntivo cabe fazer duas advertências.

17. Primeiro, tende hoje a admitir-se que na maioria dos casos a interpretação-aplicação não poderá ser reconduzida exclusivamente a operações lógico-formais. Frequentemente será necessária uma valoração. Isto assume especial importância perante conceitos caracterizados por uma elevada indeterminabilidade, como são os conceitos utilizados na previsão das normas de conflitos ${ }^{15}$.

Já é controverso se o esquema subsuntivo pode ou não ser mantido. Alguns autores entendem que a recondução dos factos à previsão normativa pode assentar não só numa subsunção, mas também num raciocínio de coordenação valorativa. Outros defendem que as operações envolvidas na aplicação da regra, apesar de envolverem uma valoração, ainda podem ser configuradas segundo um esquema subsuntivo.

Parece que pela simples circunstância de o preenchimento de uma nota conceptual ser objeto de uma valoração não fica excluída a sua idoneidade para a subsunção. Todavia, há conceitos carecidos de preenchimento valorativo que são insuscetíveis de uma definição, mesmo perante as modernas teorias de definição. Daí que se me afigure duvidoso que ainda se possa falar de subsunção a respeito da recondução dos factos a estes conceitos.

Enfim, é certo que isto diz respeito ao estabelecimento da premissa menor do silogismo judiciário - a recondução dos factos à previsão normativa - e não impede que a aplicação destas regras seja silogisticamente fundamentada. Por outras palavras, o silogismo judiciário parece possível sem o silogismo de subsunção ${ }^{16}$. Sendo também certo que este silogismo judiciário não permite fundamentar a solução segundo processos lógico-formais, mas tão-somente assegurar a racionalidade desta fundamentação.

A elevada indeterminabilidade dos conceitos utilizados na previsão das normas de conflitos não obsta, de per si, ao enunciado das suas notas características. Estas notas tanto podem ser estruturais como funcionais e na apreciação do seu preenchimento é frequentemente necessária uma valoração. $\mathrm{O}$ esquema subsuntivo pode geralmente ser mantido ${ }^{17}$, mas a aplicação da norma de conflitos transcende frequentemente as operações lógico-formais.

18. A segunda advertência é a seguinte: o esquema subsuntivo apresentado não é um esquema para a resolução de casos práticos, serve apenas para a compreensão das várias operações incluídas na qualificação em sentido amplo.

\footnotetext{
${ }^{13}$ Com efeito, uma subsunção de factos a um conceito não pode, em rigor, constituir um silogismo de subsunção - ver LARENZ [1991: 273 e seg.].

${ }^{14}$ Cf. Isabel de Magalhães Collaço [1964: 215 e segs.] e Neuhaus [1976: 114].

${ }^{15}$ Ver também SchURIG [1981: 177 e segs.].

${ }^{16} \mathrm{O}$ silogismo de subsunção serve para estabelecer a premissa menor do silogismo judiciário. Recorde-se o esquema do silogismo judiciário: temos uma situação $\mathrm{S}$, uma previsão normativa $\mathrm{P}$ e uma consequência jurídica $\mathrm{C}$; $\mathrm{P}$ é uma condição ou pressuposto que se realiza quando S é um caso particular de $\mathrm{P}$; se $\mathrm{S}$ realiza $\mathrm{P}, \mathrm{C}$ vigora para $\mathrm{S}$.

17 Em sentido diferente, ver Moura Vicente [2001: 413 e segs. e 2020: n. ${ }^{\circ} 13$ ].
} 
19. Nesta sede, importa centrar a análise na interpretação dos conceitos utilizados na previsão da norma de conflitos, que se inscreve no primeiro momento da qualificação.

20. No Código Civil, o legislador optou por utilizar na previsão das normas de conflitos conceitos técnico-jurídicos que se reportam a categorias de situações jurídicas definidas pelo seu conteúdo típico e por notas funcionais ou a questões parciais.

21. A secção do Código Civil dedicada ao Direito de Conflitos reproduz grosso modo toda a sistemática do Código Civil e, com ela, a classificação germânica das situações jurídicas em obrigações, direitos reais, relações de família e sucessões por morte.

É sabido que esta classificação não obedece a um critério unívoco, nem permite uma inserção adequada de todas as figuras. É uma classificação que reparte as matérias em centros de regulação numa ótica pragmática e que reflete certos elementos culturais.

22. As obrigações e os direitos reais são situações jurídicas agrupadas segundo um critério estrutural, i.e., atendendo ao conteúdo da situação jurídica. Na obrigação, o direito à prestação e o dever de prestar, com acento no aspeto passivo, na obrigação. No direito real, a atribuição de uma coisa corpórea que, em princípio, todos devem respeitar.

Em matéria de obrigações, a secção do Código Civil dedicada ao Direito de Conflitos também distingue, seguindo o critério das fontes das obrigações, em obrigações provenientes de negócio jurídico, a gestão de negócios, o enriquecimento sem causa e a responsabilidade extracontratual. Esta distinção também é seguida pela Convenção de Roma sobre a Lei Aplicável às Obrigações Contratuais, pelo Regulamento Roma I e pelo Regulamento Roma II.

23. Já o critério de agrupamento seguido relativamente às relações de família e às sucessões parece ser outro. É um critério de pendor funcional e institucional. Nas sucessões, a transmissão de direitos mortis causa; no Direito da Família, as situações jurídicas que respeitam à instituição familiar ${ }^{18}$.

24. Certas normas de conflitos reportam-se a questões parciais, tais como a capacidade negocial e a forma, que são requisitos de validade de negócios jurídicos.

25. A extensão do objeto da norma de conflitos deve ser aquela que convenha à sua estatuição, à remissão. A interpretação da norma de conflitos tem, pois, de atender às finalidades por ela prosseguidas, designadamente ao fundamento da conexão. Mas também deve atender aos fins gerais do sistema de Direito Internacional Privado.

26. A primeira questão que se coloca relativamente à interpretação dos conceitos técnico-jurídicos utilizados na previsão das normas de conflitos de fonte interna é a de saber a que Direito recorrer para o efeito.

27. A solução clássica consiste no recurso aos conceitos homólogos do Direito material do foro. Por exemplo, para determinar o conteúdo do conceito de obrigação, utilizado nas normas de conflitos, deveria recorrer-se à definição contida no art. $397 .{ }^{\circ} \mathrm{CC}$; para interpretar o conceito de casamento, utilizado nas normas de conflitos, à definição contida no art. $1577 .^{\circ} \mathrm{CC}$; quanto ao conceito de direito real, na falta de definição legal, haveria que atender à noção construída pelo intérprete com base nos tipos legais de direito real e no seu regime.

Neste sentido, invoca-se a "união pessoal" entre o legislador do Direito de Conflitos e o legislador de Direito material interno ou, numa forma mais ajustada às atuais conceções metodológicas, o princípio da unidade do sistema jurídico.

${ }^{18}$ Ver ainda WengLer [1981: 142 e segs.]. 
28. Contra esta tese é de assinalar que se os conceitos que delimitam o objeto da remissão tiverem o conteúdo que decorre expressamente ou por via da construção jurídica do Direito material interno eles vão deixar de fora realidades jurídicas diferentes existentes no Direito estrangeiro.

Por exemplo, o Código de Seabra definia o casamento como "um contrato de natureza perpétua entre homem e mulher". Este conceito persistiu até 1910, data em que foi admitido o divórcio. Até essa data um casamento celebrado por alemães, ou franceses, e por isso submetido ao Direito alemão, ou francês, que admitiam o divórcio, podia ser subsumido às normas de conflitos portuguesas que se reportavam ao estado e à capacidade e ao casamento? Entendeu-se que sim. Mas isto é admitir que o conceito utilizado pela norma de conflitos é mais amplo que o conceito de Direito material interno.

O problema também se pode colocar hoje relativamente ao casamento poligâmico de Direito muçulmano, uma vez que o art. $1577 .{ }^{\circ} \mathrm{CC}$ define o casamento como um contrato entre duas pessoas que pretendem constituir família mediante uma plena comunhão de vida.

Outro exemplo: a adoção era desconhecida do Código de Seabra. Suponha-se que, na vigência deste Código, $B$, alemão, adotou $A$, também alemão, na Alemanha, segundo o Direito alemão. $A$ demanda o pai adotivo, em tribunais portugueses, pedindo a condenação deste a prestar-lhe alimentos, com base na lei alemã. A pretensão de $A$ ficaria sem tutela? Existiria uma lacuna no Direito de Conflitos, sendo necessário criar uma solução ad hoc?

A doutrina dominante entendeu que as normas estrangeiras sobre adoção se poderiam reconduzir ao conceito de "estado e capacidade" da norma de conflitos do Código de Seabra (art. 27..$^{\circ}$ ), que remetia para a lei da nacionalidade dos interessados ${ }^{19}$.

Portanto, $A$ poderia invocar as referidas disposições da lei alemã como fundamento da pretensão de alimentos.

29. Em suma, há a necessidade de uma maior abertura dos conceitos das normas de conflitos. O conceito de casamento da norma de conflitos do Código de Seabra teria de ser alargado a certos casamentos dissolúveis; o conceito de estado das mesmas normas de conflitos teria de abranger a adoção.

30. Esta insuficiência da conceção clássica levou RABEL a formular uma conceção diferente, segundo a qual na formulação e, em todo o caso, na interpretação dos conceitos das normas de conflitos nos deveríamos basear no Direito Comparado ${ }^{20}$.

Por exemplo, quando a Lei de Introdução do Código Civil alemão se referia à tutela, o legislador alemão não devia ser entendido como querendo apenas reportar-se à tutela referida no Código Civil alemão, antes se reportaria, segundo a vocação universal das normas de conflitos, a todas as instituições jurídicas que têm por finalidade regular a representação ou a proteção das pessoas não inteiramente capazes que não se achem sob o poder paternal ou parental.

À conceção de RABEL é de objetar que não pode ser o Direito Comparado a decidir qual o sentido e alcance dos conceitos das normas de conflitos.

31. De iure condendo, é uma questão de política jurídica. Depende dos fins que se querem prosseguir como se conformam as previsões das normas de conflitos, qual a extensão que lhes deve ser dada. O Direito Comparado pode ser um instrumento útil para este efeito, mas não é ele que decide.

32. De iure constituto, como o Direito Comparado não é Direito positivo, não pode ser o Direito Comparado a decidir qual o alcance do conceito de uma norma de conflitos. Saber até onde o conceito utilizado na previsão da norma de conflitos abarca conteúdos jurídicos estrangeiros estranhos ao Direito do foro é um problema de interpretação da norma que o intérprete tem de resolver mediante o emprego

\footnotetext{
${ }^{19}$ Sobre a controvérsia suscitada pela questão, na vigência do Código de Seabra, ver Moura Ramos [2000: 484, e segs.] e AsCENSÃo SILVA [2000: 126 e segs.] e as referências doutrinais e jurisprudenciais contidas nestas obras.

${ }^{20}$ Ver [1931] e, posteriormente, Rabel/Drobnig [1958: 54 e segs.]. Em sentido próximo, entre nós, Helena Brito [1999: 44]. Ver ainda Id. [2017: 188-189].
} 
dos critérios de interpretação do sistema em que se integra a norma de conflitos. O Direito Comparado apenas auxilia esta tarefa.

33. Enfim, é dificilmente viável a elaboração de todo um novo sistema de conceitos, que mais não seja face à variabilidade que caracteriza as ordens jurídicas.

Como afirma Isabel de Magalhães Collaço, o método da comparação de Direitos é um instrumento, não uma solução ${ }^{21}$.

34. Pelas mesmas razões, também não se deve, em princípio, abandonar a determinação do conceito utilizado pela norma de conflitos do foro à lex causae, como defendeu até certo ponto MARTIN $\mathrm{WolfF}^{22}$. Consistiria isto, por exemplo, em subsumir na norma de conflitos do art. $46 .^{\circ} \mathrm{CC}$ tudo aquilo que na lex rei sitae fosse qualificado como direito real. Neste sentido fala-se na doutrina alemã de uma qualificação lege causae ${ }^{23}$. O sentido e alcance do conceito utilizado na norma de conflitos depende das finalidades prosseguidas pelo Direito Internacional Privado do foro, e não das opções feitas pela lex causae $^{24}$.

35. A posição adotada com respeito às normas de conflitos de fonte interna é, seguindo ISABEL DE Magalhães Collaço, a de partir do Direito material do foro, retirando da sua análise notas para a determinação do conceito empregue pela norma de conflitos, mas tendo em conta as finalidades específicas prosseguidas pelo Direito de Conflitos ${ }^{25}$.

A especialidade do Direito de Conflitos leva, em primeiro lugar, a uma certa indeterminabilidade dos conceitos aqui utilizados, de modo a poderem abranger realidades jurídicas diferentes ou desconhecidas do Direito material do foro ${ }^{26}$.

Como escreve Ferrer Correia, “o D.I.P. é por natureza um Direito aberto a todas as instituições e conteúdos jurídicos conhecidos do mundo: a sua perspetiva transcende forçosamente os horizontes do sistema jurídico interno"27.

Por exemplo, perante um direito sobre uma coisa desconhecido do Direito material português, devemos atender a notas que se retiram do Direito material interno. Como notas relevantes para a determinação do conteúdo do conceito de direito real utilizado no art. $46 .{ }^{\circ} \mathrm{CC}$ ocorrem a atribuição de uma coisa corpórea independentemente de uma relação intersubjetiva que funda pretensões perante terceiros que exprimem a sequela. Se o direito conformado pela lex rei sitae apresentar estas notas será possível reconduzir a situação à previsão da norma de conflitos do art. $46 .^{\circ} \mathrm{CC}$.

Em suma, a interpretação das normas de conflitos de fonte interna é ancorada no Direito material do foro, mas autónoma ${ }^{28}$.

36. Esta abertura dos conceitos utilizados para delimitar o objeto da remissão a realidades jurídicas estrangeiras diferentes ou desconhecidas do Direito material do foro é por vezes expressamente enunciada no texto legal. Por exemplo, o art. 30. ${ }^{\circ} \mathrm{CC}$ quando se reporta à "tutela e instituições análogas de proteção aos incapazes" 29 .

\footnotetext{
21 1964: 174 e seg. Ver também Ferrer Correia [2000: 203 e seg.].

${ }^{22} 1954$ : 54 e seg. Para um exame mais desenvolvido da doutrina de Martin WolfF, e dos limites que ela coloca à qualificação lege causae, ver Kegel/Schurig [2004 : 340 e segs.].

${ }^{23}$ Cf. Neuhaus [1976: 125] e Kropholler [2006: 123]. Também se fala, a este respeito, de uma "remissão aberta" [offene Verweisung] - cf. Neuhaus [1976: 124] seguido por Kropholler [2006: 122]. Mas a expressão é de evitar neste contexto uma vez que se trata aqui de qualificação, ao passo que a remissão diz respeito à estatuição - ver LimA PINHEIRo [2014: § 41].

${ }^{24}$ Ver ainda BatifFol/Lagarde [1993: 482 e segs.].

${ }^{25}$ Em sentido próximo, VitTa [1990 n. $\left.{ }^{\circ} 10\right]$.

${ }^{26}$ Cf. I. de Magalhães Collaço [1964: 193 e seg.], Ferrer Correia [1987: 118 e 125 e segs.] e Vitta [1990: n. $\left.{ }^{\circ} 10\right]$.

27 1984: n. ${ }^{\circ} 6$.

${ }^{28}$ Esta ideia de autonomia dos conceitos que delimitam o objeto da remissão encontra-se já aflorada em FERRER CoRREIA [1949/1950: 43-85], e TABORDA Ferreira [1959: 515 e segs.]; foi objeto de desenvolvimento sistemático por IsABEL DE Magalhães Collaço [1959: 153 e segs. e 178 e segs. e 1964: 176 e segs.].

${ }^{29}$ Cf. Ferrer Correia [1987: 133].
} 
37. Quando as finalidades do Direito Internacional Privado e a necessidade de prevenir ou solucionar certos problemas técnico-jurídicos de atuação da norma de conflitos o exigirem, pode mesmo justificar-se a formulação de regras especiais que se reportam exclusivamente a institutos jurídicos estrangeiros desconhecidos do Direito do foro. Por exemplo, o art. 64.\% CC reporta-se à validade do testamento de mão comum (testamento em que dias ou mais pessoas dispõem no mesmo ato) ${ }^{30}$, que não é admitido pelo nosso Direito material.

38. No que toca às normas de conflitos de fonte supraestadual, a interpretação dos conceitos utilizados na sua previsão deve obedecer aos critérios atrás enunciados (supra I).

\section{Interpretação dos conceitos designativos do elemento de conexão}

39. Tendo sido atrás enunciados os critérios gerais aplicáveis à interpretação das diferentes fontes de Direito Internacional Privado (I), limitar-me-ei agora a examinar a concretização destes critérios relativamente aos conceitos de nacionalidade e residência habitual.

40. Quanto à interpretação do conceito de nacionalidade, há que partir da noção geral de nacionalidade como vínculo jurídico-político que une uma pessoa a um Estado.

Mas este vínculo pode assumir diferentes significados.

41. A par do vínculo que une um indivíduo a um Estado soberano na ordem jurídica internacional, i.e., com capacidade internacional plena, há também vínculos que unem os indivíduos a Estados não soberanos ou com soberania reduzida ${ }^{31}$.

Por exemplo, nos EUA há uma nacionalidade primária, que é a do Estado federal, e uma nacionalidade secundária que se estabelece com o Estado federado do domicílio ${ }^{32}$. Na Suíça a nacionalidade primária é a do Estado federado - cantão - e a secundária a da "Confederação".

42. Por vezes fala-se de "nacionalidade" a propósito de vínculos entre indivíduos e entidades supraestaduais que não são Estados. É o que se verifica com a dita "nacionalidade comunitária" ou "europeia". Esta expressão é incorreta. A cidadania da União Europeia não é uma nacionalidade.

A cidadania europeia encontra-se prevista nos arts. 9. ${ }^{\circ}$ e 11.\%/4 do Tratado da União Europeia e na Parte II do Tratado sobre o Funcionamento da União Europeia (arts. 19. ${ }^{\circ}$ e segs. $)^{33}$.

O estatuto de cidadão da UE compreende o gozo de todos os direitos e a assunção de todos os deveres imputados às pessoas originárias de Estados-Membros. Mas os Tratados ocupam-se de certos direitos em especial, designadamente o direito de livre deslocação e permanência, o direito de proteção diplomática e, como expressão particularmente significativa da existência da cidadania da UE, o direito de votar e ser eleito para o Parlamento Europeu e nas eleições municipais do Estado de residência, por parte dos cidadãos da UE que residam noutro Estado-Membro ${ }^{34}$.

É cidadão da UE toda a pessoa que tenha a nacionalidade de um Estado-Membro (art. 9. ${ }^{\circ}$ do Tratado da União Europeia e art. 20.\%1 TFUE). A cidadania exprime a participação na definição da vontade política de uma comunidade. A atribuição da nacionalidade faculta o gozo dos direitos de participação política e é, assim, uma condição da cidadania.

A atribuição da nacionalidade é uma competência de domínio reservado dos Estados. A cidadania da UE não pressupõe qualquer nacionalidade da UE, que não existe.

${ }^{30}$ Cf. Ferrer Correia [1987: 129 e segs.]. Outro exemplo encontra-se no art. 63.\%/1 CC, quando se refere às exigências de forma especial por virtude da idade do disponente.

${ }^{31}$ Estados protegidos, vassalos, exíguos, confederados, ocupados e divididos.

${ }^{32}$ A nacionalidade secundária pressupõe sempre a nacionalidade primária.

${ }^{33}$ Ver Moura Ramos [1999: 339 e segs. e 2006]; Jorge Miranda [2010: 165 e segs.]; e Fausto de Quadros [2013: 156 e segs.].

${ }^{34}$ Ver desenvolvimento em Fausto de Quadros [2013: 160 e segs.]. 
43. Atendendo à função da norma de conflitos, a nacionalidade relevante para o Direito de Conflitos português é a nacionalidade do Estado soberano (seja ela a nacionalidade primária ou secundária).

44. O conceito de residência habitual é geralmente menos carregado de elementos técnico-jurídicos que o conceito de domicílio. É mais fácil de aplicar e gera menos divergências na sua aplicação. Daí a preferência que lhe é concedida nas Convenções internacionais, designadamente nas Convenções da $\mathrm{Haia}^{35}$, nos Regulamentos europeus e em algumas codificações mais recentes.

No entanto, este conceito designativo também suscita alguns problemas de interpretação.

45. Por residência dos indivíduos é de entender o seu centro da vida pessoal (independentemente de uma autorização de residência) ${ }^{36}$. O conceito de residência já contém uma nota de permanência. Mas a residência pode ser ocasional, caso em que há um centro de vida que, embora dotado de certa permanência, é precário.

O qualificativo de habitual exige um elevado grau de estabilidade e permanência. Uma residência só passa a ser habitual quando, tendo sido estabelecida sem um limite temporal próximo, dure efetivamente durante um considerável lapso de tempo.

Poderemos então definir residência habitual do indivíduo como centro efetivo e estável da sua vida pessoal ${ }^{37}$.

46. A utilização do elemento de conexão residência habitual com respeito a entes coletivos, nos Regulamentos Roma I e Roma II, vem introduzir uma pluralidade de conceitos de residência habitual (art. 19. ${ }^{\circ}$ do Regulamento Roma I e art. 23. ${ }^{\circ}$ do Regulamento Roma II). Com efeito, relativamente aos entes coletivos, o conceito de residência habitual tem natureza técnico-jurídica, entendendo-se que corresponde ao local onde se situa a administração central ou, no caso de o contrato, o facto danoso ou o dano dizer respeito a um estabelecimento situado noutro país, o local onde se situa este estabelecimento ${ }^{38}$.

\section{Interpretação das normas de competência internacional}

\section{Aspetos gerais}

47. O problema da interpretação e aplicação das normas de competência internacional tem certo paralelismo com o da interpretação e aplicação das normas de conflitos de Direito Internacional Privado (supra II).

48. As normas de competência internacional comportam, à semelhança do que se verifica, em regra, com as normas de conflitos de leis, um critério de conexão. Este critério de conexão pode ser indeterminado, carecendo de ser concretizado em função das circunstâncias do caso concreto. O critério de conexão indeterminado pode ser formulado positivamente (por exemplo, a regra que atribua competência aos tribunais de um Estado quando este seja o foro mais apropriado) ou negativamente (por exemplo, a regra que declara os tribunais de um Estado internacionalmente competentes para todas as ações de certo tipo, salvo se o caso não tiver uma ligação suficiente com o Estado do foro).

As normas de competência internacional vigentes na ordem jurídica portuguesa utilizam, porém, elementos de conexão determinados (por exemplo, domicílio do réu, lugar do cumprimento da obrigação, lugar onde ocorreu ou poderá ocorrer o facto danoso). Suscitam-se, pois, problemas paralelos de interpretação dos conceitos designativos do elemento de conexão.

\footnotetext{
${ }^{35}$ Cf. Von Overbeck [1992: 54 e seg.].

${ }^{36}$ Ver também art. 4. $\%$ \$ 2. ${ }^{\circ}$ do Código belga de Direito Internacional Privado de 2004.

${ }^{37}$ Cp. Jayme [1995: 206 e seg.] e Von Overbeck [1992: 54 e seg.].

38 Ver Magnus/Mankowski/Lima Pinheiro [2017: Art. 19 n. ${ }^{\circ}$ s 3-4].
} 
49. Por outro lado, a interpretação dos conceitos técnico-jurídicos utilizados para delimitar a previsão normativa e para designar os elementos de conexão coloca, em ambos os casos, a questão de saber a que sistema jurídico-material recorrer para o efeito. Por exemplo, qual o significado a atribuir às expressões "matéria contratual" e "matéria extracontratual" utilizadas em normas de competência internacional; como determinar o domicílio do réu e o lugar de cumprimento da obrigação ${ }^{39}$.

50. A resposta a estas questões é, até certo ponto, comum no Direito de Conflitos e no Direito da Competência Internacional. Aplicam-se os critérios gerais anteriormente expostos (I) e também em paralelo com o Direito de Conflitos, podemos designar por qualificação em sentido amplo a resolução do conjunto dos problemas de interpretação e aplicação da norma de competência internacional que dizem respeito aos conceitos técnico-jurídicos utilizados na sua previsão ${ }^{40}$.

\section{Normas de competência internacional de fonte interna}

51. As normas de competência internacional de fonte interna têm de ser interpretadas como parte do sistema jurídico português.

52. Se o Direito interno oferece uma definição do conceito relevante para as normas de competência internacional esta definição tem de ser respeitada. Na falta de uma definição ad hoc, na determinação do sentido e alcance dos conceitos técnico-jurídicos utilizados quer para delimitar a previsão quer para designar o elemento de conexão há que partir do Direito material interno, do conteúdo aí atribuído, por exemplo, a "obrigações", "direitos reais", "domicílio", "lugar do cumprimento", etc.

53. À semelhança do que se verifica com o Direito de Conflitos, esta interpretação é ancorada no Direito material interno, mas autónoma, por forma a atender à especialidade do Direito da Competência Internacional. Daí decorre que se possa atribuir a estes conceitos um sentido e alcance diferente do dos conceitos homólogos do Direito material interno. No que toca aos conceitos utilizados para delimitar a previsão esta diferença traduzir-se-á normalmente numa maior indeterminação, o que lhes dá uma maior abertura a realidades jurídicas estrangeiras (supra II.2) ${ }^{41}$.

\section{Normas de competência internacional de fonte supraestadual}

54. Os critérios gerais aplicáveis à interpretação das fontes supraestaduais de Direito Internacional Privado foram anteriormente enunciados (I).

55. Com respeito à Convenção de Bruxelas, o TCE sublinhou que, no que toca às normas de competência internacional, a interpretação autónoma "é a única que permite assegurar a aplicação uniforme da convenção, cujo objectivo consiste, designadamente, na uniformização das regras de competência dos órgãos jurisdicionais dos Estados contratantes, evitando, na medida do possível, a multiplicação da titularidade da competência judiciária a respeito de uma mesma relação jurídica, e em reforçar a protecção jurídica das pessoas domiciliadas na Comunidade, permitindo, simultaneamente, ao requerente identificar facilmente o órgão jurisdicional a que se pode dirigir e ao requerido prever razoavelmente aquele perante o qual pode ser demandado"42.

\footnotetext{
${ }^{39}$ Dá-se aqui por pressuposto que a interpretação dos conceitos técnico-jurídicos de "domicílio" e "lugar do cumprimento" permite concluir que se reportam a dados normativos e não a dados empíricos - ver BAPTISTA MACHADO [1982: 82 e segs.].

${ }^{40}$ Assim, Fragistas [1961: 184].

${ }^{41}$ Ver, com mais desenvolvimento, Lima Pinheiro [2019 I: 46 e segs.].

42 13/7/1993, no caso Mulox [CTCE (1993) I-04075].
} 
56. Excecionalmente, as Convenções ou Regulamentos oferecem uma definição dos conceitos neles utilizados (por exemplo, o conceito de domicílio da pessoa coletiva é definido pelo art. $63 .{ }^{\circ}$ do Regulamento Bruxelas I bis).

\section{Interpretação das normas de reconhecimento}

\section{Aspetos gerais}

57. As normas de reconhecimento de decisões externas assumem conformações muito diversas.

58. As normas de reconhecimento de efeitos de decisões externas constituem uma modalidade de norma de conflitos, na medida em que remetem para o Direito do Estado de origem da decisão ${ }^{43}$. Só estas normas integram a categoria internacionalprivatística das normas de reconhecimento ${ }^{44}$.

59. Outras normas de reconhecimento de decisões externas são normas materiais que associam à decisão externa determinados efeitos estatuídos pelo Direito do Estado de reconhecimento. É isto que, em princípio, se verifica com as normas que atribuem força executiva, valor de título de registo e força probatória às decisões externas.

60. Por vezes estas diferentes normas de reconhecimento de decisões externas encontram-se expressas nas mesmas disposições legais. É o que se verifica no regime interno de reconhecimento de decisões judiciais estrangeiras (arts. 978. ${ }^{\circ}$ e segs. CPC), que não distingue entre reconhecimento de efeitos e atribuição de força executiva. Do ponto de vista lógico, porém, é sempre possível e, para certos efeitos, necessário, distinguir entre as diferentes normas de reconhecimento que se inferem dessas disposições.

61. As normas de reconhecimento de decisões externas, quer sejam normas de conflitos ou normas materiais, podem ou não ser normas de conexão. As principais normas de reconhecimento de decisões externas vigentes na ordem jurídica portuguesa não são normas de conexão, visto que o reconhecimento não depende de uma conexão entre a situação que é objeto da decisão e o Estado de origem da decisão. Daí que o paralelismo com o Direito de Conflitos stricto sensu, no que se refere à interpretação e aplicação, seja mais limitado do que o assinalado com respeito às normas de competência internacional.

62. Ainda assim, há a assinalar que o problema da interpretação e aplicação das normas de reconhecimento de decisões externas apresenta importantes afinidades com o problema da interpretação e aplicação das normas de conflitos stricto sensu.

A interpretação dos conceitos técnico-jurídicos utilizados para delimitar o objeto da norma de reconhecimento de decisões externas coloca, à semelhança da interpretação dos conceitos técnico-jurídicos utilizados para delimitar a previsão das normas de conflitos stricto sensu, a questão de saber a que sistema jurídico-material recorrer para o efeito. Por exemplo, qual o significado a atribuir às expressões "matéria civil e comercial" e "direitos privados" e aos termos "decisão" e "divórcio".

$\mathrm{O}$ mesmo se diga, com respeito às normas de reconhecimento de decisões externas que comportem elementos de conexão, quanto à interpretação dos conceitos técnico-jurídicos utilizados para designar os elementos de conexão e à concretização dos elementos de conexão que constituem dados normativos.

63. A resposta a estas questões é, até certo ponto, comum ao Direito de Conflitos stricto sensu, ao Direito da Competência Internacional e ao Direito de Reconhecimento, em conformidade com os critérios gerais anteriormente enunciados (I).

\footnotetext{
${ }^{43}$ Ver, sobre o conceito de reconhecimento, Lima PinheIro [2019: § 90].

${ }^{44}$ Sobre esta categoria, ver Lima PINHEIRo [2014: § 14 B].
} 
64. Também em paralelo com o Direito de Conflitos stricto sensu e com o Direito da Competência Internacional, podemos designar por qualificação em sentido amplo a resolução do conjunto dos problemas de interpretação e aplicação da norma de reconhecimento de decisões externas que dizem respeito aos conceitos técnico-jurídicos utilizados na sua previsão ${ }^{45}$.

65. O objeto da norma de reconhecimento de decisões externas é a própria decisão externa. Esta norma de reconhecimento reporta-se a uma decisão externa com certas características e atribui-lhe determinada relevância jurídica na ordem jurídica local. Isto é assim mesmo quando a norma de reconhecimento se reporta a uma decisão externa que produz determinado tipo de efeitos na ordem jurídica do Estado de origem e opera uma receção destes efeitos na ordem jurídica local.

\section{Normas de reconhecimento de fonte interna}

66. Aplicam-se aqui, com as devidas adaptações, as considerações que foram tecidas com respeito às normas de competência internacional de fonte interna (supra III. 2).

67. É concebível uma qualificação da decisão externa segundo o Direito do Estado de origem. Por exemplo, seria de reconduzir ao conceito de "decisão sobre direitos privados" das nossas normas de reconhecimento a decisão que no Estado de origem seja como tal considerada. Mas a qualificação segundo o Direito do estado de origem é de excluir, uma vez que cabe ao Direito do Estado de reconhecimento decidir quais as decisões a que confere relevância jurídica na ordem interna e quais as condições de que depende essa relevância.

68. Uma "dupla qualificação", que exija a coincidência entre a qualificação feita perante o Direito do Estado de origem e a qualificação segundo o Direito do Estado de reconhecimento, também é de recusar, porque dificultaria o reconhecimento de decisões externas.

69. A qualificação deve ser feita segundo o Direito de Reconhecimento português, mas com base numa interpretação autónoma dos conceitos utilizados para delimitar a previsão da norma de reconhecimento. Quando estes conceitos se reportam a características das decisões externas que dizem respeito, designadamente, à natureza da entidade que as proferiu, à qualidade em que atuou esta entidade ou à eficácia da decisão na ordem jurídica do Estado de origem, torna-se necessária uma caracterização segundo o Direito do Estado de origem ${ }^{46}$.

Assim, por exemplo, a qualificação de uma decisão estrangeira como "decisão sobre direitos privados" para efeitos do art. $978 .^{\circ} \mathrm{CPC}$, deve ser feita segundo o critério definido perante o Direito de Reconhecimento português e com base numa interpretação autónoma.

70. Por "decisão" entende-se qualquer ato público que segundo a ordem jurídica do Estado de origem tenha força de caso julgado ${ }^{47}$. Há que aferir perante o Direito do Estado de origem se a decisão foi proferida por um órgão público e se tem força de caso julgado.

71. Pelo que toca ao caráter "privado", o que importa é o objeto da decisão e não a natureza do tribunal que a proferiu ${ }^{48}$.

\footnotetext{
${ }^{45}$ Em geral, sobre a qualificação dos conceitos utilizados nas normas de reconhecimento, ver VITTA [1979: 114 e seg.] e MartinY [1984: n. ${ }^{\circ}$ s 185 e seg.]. No sentido de as questões de saber o que se deve entender por "decisão sobre direitos privados" e por "tribunal estrangeiro" poderem ser configuradas como problemas de substituição, ver BASEDOW [1992: 148].

${ }^{46}$ Em sentido convergente, MarTiny [1984: n. $\left.{ }^{\circ} 186\right]$.

${ }^{47}$ Cf. Morelli [1954: 311], Martiny [1984: n. ${ }^{\circ} 487$ e segs.] e Schack [2017: n. ${ }^{\circ}$ s 102 e 906]. Em sentido convergente, FerRER CORREIA [2000: 455 e seg.]. Sobre o problema do reconhecimento das providências cautelares, ver BARIATTI [1995: 1225] com mais referências, Martiny [1984: n. ${ }^{\circ}$ s 492 e segs.] e SchaCK [2017: n. ${ }^{\text {ss }} 914$ e segs.].

${ }^{48}$ Cf. Isabel de Magalhães Collaço [1963: 25] e Ferrer Correia [1982: 107 e 2000: 455].
} 
A decisão deve ter por objeto uma relação que no Estado de reconhecimento seja considerada "privada" ${ }^{4}$. Para efeito desta apreciação a relação tem de ser caracterizada juridicamente perante a ordem jurídica do Estado de origem. É uma qualificação segundo o Direito de Reconhecimento do foro com base numa caracterização feita perante a ordem jurídica do Estado de origem.

\section{Normas de reconhecimento de fonte supraestadual}

72. Também aqui se aplicam, com as devidas adaptações, as considerações anteriormente expostas (I).

73. A definição autónoma dos conceitos técnico-jurídicos utilizados para delimitar a previsão das normas supraestaduais de reconhecimento de decisões externas é excecional. Constitui exemplo a definição de "decisão" contida no art. 2.\%a do Regulamento Bruxelas I bis.

74. Na falta de uma definição autónoma, as soluções possíveis para o problema da qualificação são fundamentalmente três: a qualificação segundo o Direito do Estado de origem, a "dupla qualificação" e a "qualificação autónoma".

Todas estas soluções foram defendidas, perante a Convenção de Bruxelas sobre a Competência Judiciária e a Execução de Decisões em Matéria Civil e Comercial (1968), com respeito à qualificação de uma decisão como relativa a "matéria civil e comercial".

Num primeiro momento, alguma doutrina inclinou-se no sentido de uma qualificação segundo o Direito do Estado de origem ${ }^{50}$.

O TCE, porém, estabeleceu com a decisão proferida no caso Eurocontrol uma orientação no sentido da autonomia da qualificação feita pelo tribunal de reconhecimento ${ }^{51}$. Como já se assinalou, entende-se por "qualificação autónoma" uma qualificação baseada numa interpretação autónoma dos conceitos utilizados na previsão destas normas de reconhecimento. Isto não exclui que o conceito assim interpretado se reporte a características das decisões que devem ser apreciadas segundo o Direito do Estado de origem ou segundo o Direito interno de outro Estado. Assim, parece que a questão de saber se uma decisão judicial, por ter por objeto uma relação conexa com o exercício de poderes de autoridade, não é reconduzível ao conceito de "matéria civil e comercial", exige uma consulta do Direito do Estado direta ou indiretamente implicado na relação ${ }^{52}$.

\section{Considerações finais}

75. Para a interpretação das proposições de Direito Internacional Privado vale muito da temática geral da interpretação jurídica, sendo especialmente de sublinhar os desafios resultantes da indeterminabilidade dos conceitos utilizados nestas proposições e da unidade entre interpretação e aplicação das normas que exprimem.

76. O exame dos problemas específicos colocados por estas proposições revela uma vasta identidade nos três complexos normativos abrangidos pelo Direito Internacional Privado enquanto disciplina jurídica (Direito de Conflitos, Direito da Competência Internacional e Direito de Reconhecimento), o que demonstra que esta abrangência não é só justificada pelos múltiplos e estreitos nexos funcionais que intercedem entre esses complexos normativos mas também por uma afinidade da sua problemática técnico-jurídica e dos critérios que orientam a sua solução.

\footnotetext{
${ }^{49}$ Cf. Martiny [1984: n. ${ }^{\circ}$ 500] e Schack [2017: n. ${ }^{\circ}$ s 906 e segs.].

${ }^{50}$ Cf. Bülow [1965: 476 e seg. n. 10], Goldman [1971: 9], Weser [1975: 223 e seg.] e Schlosser [1977: 459].

${ }^{51}$ 14/10/1976 [CTCE (1976) 629]. Ver an. de Droz [1977: 779 e segs.]. Ver também TCE 14/7/1977, no caso Bavaria [CTCE (1977) 535] e TeIXeIRA De Sousa [2002: 680 e seg.].

${ }^{52}$ Cp., porém, Lima Pinheiro [2019: § 84 B].
} 